\title{
An Analysis of Common Security and Defence Policy's (CSDP) Strategic Communication (StratCom)
}

\author{
Kieran Doyle ${ }^{1} \&$ Tedla Desta $^{1}$ \\ ${ }^{1}$ Edward M. Kennedy Institute for Conflict Intervention, Maynooth University, Ireland \\ Correspondence: Kieran Doyle \& Tedla Desta, Edward M. Kennedy Institute for Conflict Intervention, Maynooth \\ University, Ireland. E-mail: kieran.doyle@mu.ie; kinwttw@gmail.com
}

Received: July 23, 2020

doi:10.5539/jpl.v14n2p56
Accepted: December 23, 2020

Online Published: December 27, 2020

URL: https://doi.org/10.5539/jpl.v14n2p56

\begin{abstract}
Strategic communication (StratCom) is established as one of the key functions and interests of contemporary organisations and governments. The usefulness and importance of strategic communication becomes even more essential when the organisation is defence and security-focused or involved in crisis management. The objective of this study was to assess the strategic communication practices, and inherent challenges of communicating Common Security and Defence Policy (CSDP) and present relevant reflections. A documentary analysis of the relevant EU websites and social media pages of 16 CSDP missions and operations was conducted. This was supplemented with eight key-informant interviews with Press and Public Information Officers (PPIOs) of CSDP and EU strategists.

The research demonstrated that most CSDP missions and operations are present on most social media platforms but they often garner very small number of likes, comments, shares, replies or interactions from their targeted audiences. Features of an echo-chamber are also observed. The study also found that public affairs (information) and public diplomacy were the two main forms of strategic communication that the CSDP utilises. CSDP's strategic communication also tends to take a one-way StratCom process. The challenges faced in terms of StratCom by CSDP are not uniform; they are contextual ranging from resource, translation to mismatch of expectations. The major challenge, however, emanates from the structural problems of CSDP or the EU itself that are beyond the European External Action Service (EEAS) or the relevant Press and Public Information Offices (PPIOs). The study recommendations include quicker EU level political and policy compromise on CSDP, training and resource improvements for StratCom, 'storytelling and use of real people', highlighting gender, rights and local ownership, increasing the link with the international media and regular and appropriate self-appraisals.
\end{abstract}

Keywords: strategic communication, policy, Europe, politics, development

\section{Introduction}

Security and defence are crucial elements of peacebuilding in this highly interconnected and inter-dependent world. As many developed countries, as well as increasing number of developing countries, have started to show relative peace and stability, several countries around the world are still embroiled in internal and inter-state conflicts and crises. Despite the efforts of several inter-continental, regional and international security and peacebuilding institutions and blocs, the conflicts and crises have not been fully prevented, contained or resolved. One amongst these blocks is the European Union (EU's) Common Security and Defence Policy (CSDP). The CSDP's international operations and missions in third countries have achieved recognisable changes within the crisis locations they have been deployed to. According to the CSDP's 2016 Annual Report, in that year alone, it conducted a major training and capacity building programme, mentoring and prosecutions as well as facilitation of dialogue and agreements, saved over 20,000 lives (especially in the Mediterranean), helped in the reduction of piracy, and supported capacity building and policy formulations.

The EU's CSDP, unlike many other security blocs and forces, stands out since the EU directs it. The EU has a positive record of accomplishment as a peacebuilding bloc rather than as an aggressive and invading bloc and the nature of its completed CSDP missions. CSDP's role in this inter-dependent and co-existing world can be understood in two ways. On the one hand, it protects the EU from insecurities and crises in the Union's neighbourhood and on the other hand, it builds the capacities, security and peace of third countries, where EU missions are deployed. Gender, human rights and human security within the CSDP are central and appear in many 
places in the document. CSDP, however, has its own features that are continuously debated such as national sovereignty of member states and their relationship with CSDP.

Has CSDP effectively or strategically communicated its policy, its missions and operations? A few CSDP missions have their own social media pages. From our preliminary reading, it is also unusual to observe CSDP in the legacy international media. The positive effect of CSDP missions and operations, may not have been strategically communicated. The findings of this study also reflects the fifth strategic priority of the EU Global Strategy on Foreign and Security Policy, introduced in June 2016, on public diplomacy. The EU's official Europa.eu website highlights two main tents of the public diplomacy strategy "the EU is enhancing its strategic communications, which involves upgrading the consistency and speed of messaging" of EU's values and actions. These include rebuttals of disinformation as well as promotion of "open and inquiring media environment" and "working with local players through social media."

Focusing on the communicative aspect of the CSDP and using the theories and literature of strategic communication as analytical lens, this research investigates how the CSDP is communicated to its audiences, particularly in mission and operation locations. After the introduction, a literature review and methodology section will follow, with subsequent presentation of research findings, discussion and final conclusions.

\section{Literature Review}

\section{The Common Security and Defence Policy (CSDP)}

\subsection{Origins and Evolution of the CSDP}

The discussions and idea of the CSDP started in the aftermath of World War II, when in 1948, the United Kingdom, France, and the Benelux countries signed the Treaty on Economic, Social and Cultural Collaboration and Collective Self-Defence, also known as the Treaty of Brussels (Carrasco et al., 2016). This was followed by the formation of the military alliance known as the Western European Union (WEU) until the post-Cold War years of conflicts and crises in Europe and the rest of the world. The Common Foreign and Security Policy (CFSP) was introduced in the Maastricht Treaty in 1993.

Article J.4 of the Maastricht Treaty stated that CFSP comprises "all questions related to the security of the Union, including the eventual framing of a common defence policy, which might in time lead to a common defence" (Carrasco et al., 2016:18)

Following the crisis in Kosovo, the UK and France agreed at Saint Malo in 1998 that the EU must have "the capacity for autonomous action, backed up by credible military forces, the means to use them and a readiness to do so, in order to respond to international crises'

The EU Member States decided in Helsinki to build a Common European Security and Defense Policy (CESDP) backed by credible military forces and appropriate decision-making structures (Carrasco et al., 2016:18).

The 'Berlin Plus Agreement' which "gave the EU, under certain conditions, access to North Atlantic Treaty Organisation (NATO) ${ }^{1}$ assets and capabilities," was also adopted at the same period. The Santa Maria Da Feira meeting reaffirmed the idea of a CESDP respecting the principles of the UN Charter. The first European Security and Defense Policy (ESDP) mission was launched in 2003 in Bosnia and Herzegovina, when in the same year, the European Security Strategy (ESS) known as 'A Secure Europe in a Better World' was formulated and later in 2008 the revised 'Providing Security in a Changing World' focusing on "human security" (Carrasco et al., 2016: 19). After the Lisbon Treaty in December 2009, the ESDP was renamed as the Common Security and Defence Policy (CSDP). The Lisbon Treaty was important in the development of the CSDP in terms of its inclusion of the notion of "political and military solidarity" and gave the role of guiding the CSDP to the High Representative for Foreign Affairs and Security Policy (Carrasco et al., 2016: 19).

Common issues that CSDP missions or operations tackle are maritime security, border management, terrorism, organised crime, regional conflicts and state failure. The EU works in coordination and co-operation with the UN even if the invitation came directly from local authorities. The records of the EU's military involvement in Africa indicate a preference for civilian missions in low-risk security contexts which affect the EU, such as terrorism (anti-terror civilian mission in Niger), irregular migration in EUNAVFOR MED and drug trafficking (Carrasco et al., 2016). Carrasco et al. (2016) state that the European Union's (EU) foreign policy, the Common Security, and

\footnotetext{
${ }^{1}$ NATO established the Strategic Communications Centre of Excellence (NATO StratCom COE) in 2014 in Latvia to provide "comprehensive analyses, timely advice and practical support to the Alliance, designs programs to advance doctrine development, conducts research and experimentation to find practical solutions to existing challenges."
} 
Defence Policy's (CSDP) principal objectives are "the promotion and protection of human rights and support for democracy and the rule of law." EU has launched over thirty missions and operations since 2003, ranging from large-scale military and civilian deployments, to short-term support or deployments in support of missions led by other international security actors. In 2016, there were seventeen ongoing CSDP missions and operations - eleven civil missions and six military operations - primarily in Africa, the Middle East and Eastern Europe. These crisis management missions by the military are consent-based, based on human rights values and are "multidimensional and complex" (Carrasco et al., 2016). The document repeatedly mentions the centrality and important place of gender, human rights and hence human security in CSDP.

Up until 2016 at least eight EU and UN missions and operations in Afghanistan, the Central African Republic (CAR), the Democratic Republic of Congo, Israel/the Palestinian Territories, Kosovo, Libya, Mali and Somali were deployed. In addition, significant collaborations between the EU and NATO, the EU and the African Union, EU-OSCE, and EU-ASEAN were in train (Carrasco et al., 2016). Participation of third states in this peacebuilding work may pose additional obstacles to the achievement of mission objectives in full respect of international standards and in promoting EU values that they might not share or interpret in the same terms as EU Member States. Another aspect to be taken into consideration is the multidimensional nature of CSDP missions and operations that can also predetermine the applicable legal framework (Carrasco et al., 2016). The EU High Representative for the Union in Foreign and Security Policy CFSP, Federica Mogherini, currently heads the CSDP and outputs such as the Political and Security Committee (PSC), the EU Military Committee (EUMC) and the EU Military Staff (EUMS) coordinate it.

There are criticisms and debates regarding the CSDP within both policy and academic circles. Some of the supporters of the CSDP argue that most EU countries face similar security threats and therefore, they should work together, this would be an addition to efforts of the US through NATO and gives the EU the independence to "pursue its own defence agenda". On the other hand, critics would argue that elected representatives rather than the High Representative should only make big national or continental decisions such as war, it diverts resources from NATO and there is a bias in terms of deployment since some EU countries prioritise their former colonies (James, 2015).

CSDP operations since 2003 have shown the expansion of the EU's capabilities in the types and geographic reaches of security tasks and the relationship created with third countries and agencies (Smith, 2014).

CSDP should be viewed as examples of opportunistic capacity-building in the CSDP, intended to help provide the EU with vital operational experience and to help raise the EU's profile, and credibility, as a global security actor (Smith, 2014).

However, despite some system related and mission debates, the CSDP has achieved several successes and evolved through time. The EU also used the previous missions as "lessons learned" experiences to improve its performance; despite challenges around lack of political will among EU governments, operational planning and intelligence capability issues (Smith, 2014).

\subsection{Strengths and Challenges}

Brexit, The Lisbon Treaty, Right Wing Politics, the rise of Trump, problems with the EU-wide CSDP strategy, financial and political will, its ad hoc nature, pooling and sharing imbalance, and the NATO or CSDP debates are some of the challenges CSDP has to grapple with.

As Smith (2014) notes policy planning capacity and a more robust intelligence analysis capacity are crucial for the future of the EU/CSDP. The local ownership strategy of the CSDP could give the EU a better intelligence analysis edge than other similar international agencies. Similarly, the embeddedness of human rights, gender and thereby, human security within the principles and discourses of CSDP means it has the potential to flourish and be accepted in many parts of the world. Nulle (2014) offers three main recommendations for CSDP such as highest-level political debates, self-repositioning strategic debates and lowering of expectations to focus on sustainable longterm objectives. The author stresses that "shared defence" is crucial for the safety and prosperity of the EU and beyond in the world.

One of several CSDP related reports that studied the communication features of EU's missions within CSDP is Dijkstra's 2012 paper "Agenda Setting in the Common Security and Defence Policy: An Institutionalist Perspective." The paper notes that the EU's international missions under the CSDP contributed to stability, peace deals and local capacity building. There was a notable agenda setting at both the "political and administrative levels" in the individual operations. Javier Solana, former Secretary General of the Council of the European Union and representative of CFSP, is credited for his agenda setting roles especially in the Bosnia, Chad and Kosovo 
missions and subsequent EU operations. It is now also changing the public diplomacy and self-presentation of the EU to the wider public, and audience. Ejdus (2017) notes that the EU's High Representative Federica Mogherini issued the Global Strategy for the European Union's Foreign and Security Policy, 2016, which stresses that the EU will "work through development, diplomacy, and CSDP" on "locally owned" Security Sector Reforms (SSR) in partner countries (EU 2016c: 26). Local ownership is one of the ways that CSDP has been able to capitalise on this, to strategically communicate the intentions of the EU in practical terms.

\subsection{Strategic Communication (StratCom)}

To understand strategic communication, the discussion has to begin by defining the meaning of strategy. Holtzhausen and Zerfass (2014) note that the word strategy is derived from a Greek word, which denotes a military commander. The authors trace the academic operationalisation of strategy to Prussian theorist Carl von Clausewitz (1780-1831) and his treatise magnum opus Vom Kriege (On War). The term in academia was first applied in organization theory in the 1950s according to Hatch (1997) quoted in Hallahan et al. (2007:12) to explain "how organizations compete in the marketplace, obtain competitive advantage, and gain market share." The term is often used within the military but when we apply it in the context of communication, it portrays a much-advanced concept that is often conflated with or misunderstood as public relations or marketing, which relates to the art of war.

Vernon (2013) argues that the public relation officers become strategic communicators when they develop the "strategic mindset" and that is the reason why the public relation and the marketing officer share cross-functionality in writing, editing, or rhetoric but lack the strategic mindset. On the other hand, Wilbur (2017) argues that strategic communication integrates more than public relations and marketing such as at least four academic sub-disciplines like marketing/public relations, corporate communication, business communication and organisational behaviour. Falkheimer (2015) explains that strategic communication could be defined as internal (between management and employees) or external (organisations and the surrounding world). Some recent research reports by the NATO also define StratCom as a mind-set "mind-set which implies placing communications at the heart of a strategy" (LangeIonatamishvili and Svetoka, 2015: 104).

Strategic communication involves the ability of the strategist to take a broad and an in-depth look at the organization and assess where effective communication is most needed and develop a plan that makes it happen (Durutta, 2006: 20). They develop communication plans for the organisation, which includes situation analysis, message statement, target audience and stakeholders, tactical implementation, and evaluation (Potter, 2006: 8287). Strategic communication officers are part of the strategic management team of an organisation. One of the first academic definitions of strategic communication states that strategic communication is "intentional" and therefore theoretically requires a "purposeful actor, rational and deliberate decision-making, and the implementation and evaluation of a strategic communication program" (Hallahan et al., 2007: 12). Hallahan et al. (2007) state that strategic communication is different from communication in general or integrated communication because its "focus is how an organization communicates across organizational endeavours" and especially how the organization "presents and promotes itself through the intentional activities of its leaders, employees, and communication practitioners." Holtzhausen and Zerfass (2013) defined strategic communication as the practice of "deliberate and purposive communication that a communication agent enacts in the public sphere on behalf of a communicative entity to reach set goals." Another author, Eder (2011) defined strategic communication as the process of "massing information among all agents of public information at a critical time and place to accomplish a specific objective." All the definitions stress that strategic communication is different from many other types of communication or information in the fact that is planned, intentional, timed, with specific objectives, places and goals.

As this article deals with the case of strategic communication in the context of a security defence and security entity, it is perhaps appropriate to dwell on prior definitions of strategic communication by defence organisations with the foremost history the application of strategic communication in their organisations. Phillips (2012) offers two definitions of strategic communication, one offered by former U.S. President Barack Obama's administration's "National Framework for Strategic Communication" and the US Department of Defense (DoD). The first definition of the National Framework describes strategic communication as,

The synchronization of words and deeds and how selected audiences, as well as programs and activities will perceive them deliberately aimed at communicating and engaging with intended audiences, including those implemented by public affairs, public diplomacy, and information operations professionals.

DoD's definition of strategic communication, on the other hand, is 
focused United States Government efforts to understand and engage key audiences to create, strengthen, or preserve conditions favourable for the advancement of United States Government interests, policies, and objectives through the use of coordinated programs, plans, themes, messages, and products synchronized with the actions of all instruments of national power.

The first definition by the National Framework is slightly similar to the definition offered by Hallahan et al. (2007). It is a broader definition nonetheless, the watchword particularly highlighting in the definition is the focus on the deliberateness of strategic communication. Deliberateness is absent in the classic studies and principles of journalism, which follows the News beats. In both the DoD's definition and the definition of the National Framework, the synchrony of what is communicated and the real actions implemented is stressed as very crucial in strategic communication. The DoD's definition, in particular, explains that strategic communication is about understanding not the whole audience but key audiences. A media outlet that somewhat fulfils this definition is the Voice of America (VoA). VoA, transmitted only to audiences outside of America, has a mission of "keeping the world favourably informed about the lifestyle and citizens of the United States through magazines, films, and press releases as well as through shortwave broadcasts over the VoA" (Uttaro, 1982: 120).

The third definition extracted from Report of the Defense Science Board Task Force on Strategic Communication published in 2004 defined strategic communication as

A variety of instruments used by governments for generations to understand global attitudes and cultures, engage in a dialogue of ideas between people and institutions, advise policy makers, diplomats, and military leaders on the public opinion implications of policy choices, and influence attitudes and behaviour through communication strategies.

One of the themes or an observed connotation of the above definitions is that strategic communication tends to have similar features of propaganda. However, the third definition of the Task Force relate to the main features of intelligence work essentially tasked to policymaking purposes. Understanding, engaging and influencing are terms and ideas that appear in all the definitions of strategic communication.

Paul (2011) argues that strategic communication is not a patchwork but is "about explanations (preferably in terms that are comprehensible to, and that resonate with, relevant populations), about finding shared perspectives and common ground, about compromise, about credibility, about legitimacy, about partnership, about support" or as Falkheimer (2015) argues, "strategic communication is not inherently good (creating interaction) or bad (propaganda)." Paul (2011) lists four unassailable cores of strategic communication, which are Informing, influencing and persuading, clear objectives (which makes strategic communication "strategic"), coordination and deconfliction are necessary to avoid information fratricide and actions communication such as policies. Falkheimer (2017) recount that in a study of strategic communication in a sample of Norwegian companies, respondents viewed strategic communication as less important for corporate success than sales, finance, HR, strategic planning and marketing respectively, but slightly more important than security, IT and legal affairs (Brønn, 2014).

According to Falkheimer (2015), the main theory behind public relations and later strategic communication is James E. Grunig's Excellence Theory, which led to the formulation of the five models of public relations: the publicity model or one-way communication (propaganda), the public information model (with no feedback), twoway asymmetrical model, the two-way symmetrical model (for mutual understanding with stakeholders). The fifth model is the mixed-motive model describes "the communication process as a negotiation, where the goal is to achieve win-win for both communicators: the organisation and the stakeholders."

Nowadays, communication is being augmented by the wider availability of data and sometimes the privileged access to data. Big data offer unique algorithmic information of a website visitor's preferences and interests; it also includes the complete DNA profile of a single human being, which can help in better studying or persuading the person finally making survey research redundant. The availability of big data within organisations gives strategic communicators the strategic edge over journalists or academic researchers (Holtzhausen and Zerfass, 2014).

\subsection{Characteristics and Forms of Strategic Communication}

There are four major characteristics that distinguish strategic communication from other types of public information: Tactical audience selection of a niche group, breaking down stovepipes (duplication) of communication, public diplomacy of national or organisational branding or name, and rapid, comprehensive responses to issues (Eder, 2011).

Farwell (2012) lists four main forms of Strategic Communication such as: 
- Psychological Operations (PSYOP) or Military Support Operations (MSO): This form of communication targets "foreign audiences to influence their emotions, motives, objective reasoning, and ultimately the behaviour of foreign governments, organisations, groups and individuals." using words, actions, images or symbols. This type of strategic communication particularly relates to the Voice of America (VoA) example.

- Propaganda: It is manipulation in this case and the best way to point out the difference between PSYOP and propaganda is to highlight that propaganda is a "process designed to persuade people to fight" whereas PSYOP is "propaganda designed to persuade the opposition NOT to fight." Public affairs (information) and public diplomacy ${ }^{2}$ are the other two forms of strategic communication that Farwell (2012) mentions.

The four components of strategic communication have at least three common elements that are crosscutting according to Cornish et al. (2011: 4):

First is the need to inform, influence and persuade audiences at home and abroad, whether friendly, adversarial or merely a member of the public. Second is the need to promote coordination across government to avoid what the US Army calls 'information fratricide'. Third, the need to communicate strategically is itself dependent on the ability to communicate actions to all affected and interested audiences and to ensure that actions are themselves communicable, i.e. complementary to and supportive of strategic objectives.

The approaches that defence and security agencies would apply strategic communication could be highly different from the ways in which civilian agencies would appropriate the approach. Most non-defense orientated government agencies as well as private and non-governmental organisations may often apply public affairs and public diplomacy to reach their targets.

Coordinated by the EEAS, the EU has its own CSDP Startcom strategy and officers. Outside of the CSDP, the EEAS currently has three Strategic Communications Task Forces, which deal with the Eastern partnership countries and Southern neighbourhoods (Middle East and North Africa (MENA) region), and the Western Balkans ${ }^{3}$. Except the Easter Task Force, which was launched in 2015, the other two were launched in 2017.

One of the rare analyses on EU's strategic communications was published in 2016 by the EU parliament. The indepth analysis report notes "coherent hostile 'strategic communications' campaigns were directed against the EU mainly with Russia targeting "EU's nature and policies" while ISIL targets EU's values" (EU Parliament, 2016: 29). The report stresses that a credible strategic communication (defensive or offensive) "needs to be built on the search and analysis dissecting the problem (s), the audience (s), and the message (s) and to be planned and implemented accordingly" (ibid. 29-30). However, budgets for the strategic communications purposes are not "negligible at all." Our literature review also do not detect research on CSDP's strategic communication either conducted in the missions and operations or outside other institutions.

\section{Methodology}

The research approach adopted for this research is qualitative. Two main research methods are employed: Document Analysis and Semi-Structured interviews with key informants. The documentary analysis involved the analysis of reports, documents and the PR or media such as the social media pages used by offices responsible within the CSDP framework. The interview method involved semi-structured interviews with key personnel within the EEAS and wider CSDP apparatus. The interviewees were selected based on their knowledge and involvement within the CSDP and especially internal and external communication roles in relation to CSDP. More interviewees were recruited using the Snowballing method. Interviews were conducted using three methods: face to face, using email and telephone. The length of the interviews was between 30 minutes and one hour. A total of eight interviewees took part in the interview. Key informant interviews "involve interviewing a select group of individuals who are likely to provide needed information, ideas, and insights on a particular subject" (Kumar, 1989: 7). The interview questions are derived out of the literature review and the preliminary findings of the secondary (document analysis).

\footnotetext{
${ }^{2}$ Sharp, quoted in (Melissen, 2005: 11) defined it as "the process by which direct relations with people in a country are pursued to advance the interests and extend the values of those being represented" Public diplomacy is categorised under strategic communications. Public diplomacy is often associated with civilians while the bigger and broader umbrella of strategic communication (StratCom) is with the military. ${ }^{3}$ Personal interview with a Stratcom officer of the EEAS held in Brussels, Belgium on November 6, 2017.
} 
Therefore based on the above literature review and the analysis of CSDP missions and operations' media presence, the following research questions are asked.

- How does the CSDP apply strategic communication?

- What forms of StratCom does CSDP employ? What are the intentions?

- Who are the targets?

- What are the challenges that CSDP faces in the strategic communication to its audiences and what are the possible solutions?

\section{Findings and Discussion}

This section presents findings from the analysis of the CSDP social and traditional media presence and the key informant interviews conducted with select stakeholders of CSDP. The presentation of the findings is followed by a discussion of the findings against the research questions and the literature.

\subsection{Analysing the CSDP Online Media}

The parent account/the channel of the CSDP channel is known as the European External Action Service (EEAS), which created the "EUSecurityandDefence". The EEAS also owns other channels such as Europe Aid-EU in the world, EU NEIGHBOURS, the European Defence Agency, the European Commission, the Council of the EU, the European Parliament, the UNHCR/the UN Refugee Agency, the EUinThailand, the EUinIndonesia, the European Union in Senegal, the EUintheUS, EULEX Kosovo and the EU in Kyrgyzstan. The most subscribed channel is the UNHCR channel with 49, 000 subscribers followed by the European Commission with 40,000 subscribers and the European Parliament with 26,000 subscribers. The least subscribed channel is the EU in Kyrgyzstan, which was only created two years ago.

The CSDP's Flickr account has English and French descriptions, the English version reads, "Under its Common Security and Defence Policy (CSDP), the EU can decide to launch military and/or civilian missions to ensure peace and security in troubled regions. With 27 operations (finished or on-going) deployed on 3 continents since 2003, the EU's role as a security player is rapidly expanding." Most of the tweets focused on the works, activities and events in relation to EUPOL Afghan's. Noticeably, the account holder sent best holiday wishes to all Muslims during each Muslim holiday. Can we call it a charm offensive? Most of the posts on the Facebook pages of the CSDP mission pages contain photographs but are often liked by less than 20 people and receive no comments. The EU Naval Force Somalia - Operation Atalanta (EU NAVFOR - Atalanta) is an active Facebook page with less than 20 likes and less than 2-3 comments under most posts. A search for the "Common Security and Defence Policy (CSDP)" on Google News resulted in 42 Google News pages or 1,020 results in 0.16 seconds. The majority of the media outlets that reported on the CSDP were Europe based local media outlets.

The table in Appendix 1 shows the ten civilian and six military missions and operations that the EU has been active in 2016. Appendix 1 shows that there is an inconsistency in terms of the presence of CSDPs missions and operations on social media platforms. Although most of the pages have their own websites, they do not all have presence across the four major social media platforms. EUPOL Afghanistan, EU NAVAL Somalia, the EU Training Mission Mali, the EU Advisory Mission Ukraine, the EU Force in Bosnia and Herzegovina and EU NAVFOR (Southern Mediterranean) are present on Facebook, Twitter, YouTube and Flickr or Instagram. Since the Afghanistan page has been inactive since last year, CSDPs that are present on the four platforms and only five out of the 16 missions and operations have a relatively active social media presence. The EU Mission in Rafah does not have any social media presence except its own website, which publishes News and press releases. The majority of the missions are only present on one or two platforms such as Twitter or Facebook.

Most of the social media accounts were opened at different times, for example, EUAM Ukraine's Twitter page was opened in November 2014 but the Flickr and YouTube accounts were opened in 2015. The common time gaps in terms of posting two to four days. The majority of the posts on YouTube, Facebook, Twitter or Flickr do not often garner many likes, comments or shares. The Facebook posts of almost all the missions often garner less than 10 likes and less than five comments per post. It is also important to know the identity of these few people who continue to interact with the missions and operations on social media. Most of the images, video clips and texts posted on their social media pages portray common messages of the training of local staff in the field and offices, award ceremonies and official visits and mainly on the record of achievements of CSDPs. For example, the Twitter posts of the Afghanistan mission regularly wished Muslims happy fasting seasons and holidays. The posts attempted to acknowledge their trainees or beneficiaries, while emphasising the top-down transmission of the training courses and support from the EU to the regions of the crises. Despite what can be described as mostly positive, human rights and dignity focused posts on social media pages of CSDP, their strategic reach, and possible 
reception by the target audience is not discerned from a review of their social media page. This would be further explored on the key informant interviews conducted with CSDP communication staff and stakeholders.

\subsection{Interview Findings}

The section below presents the main findings from eight key-informant interviews held with staff of various CSDP missions and operations and the EEAS.

\subsection{Communication}

During the interviews, CSDP communication staff outlined that they communicate their activities with stakeholders and the wider audience using digital media tools and mainly social media, which have now become dominant. CSDP missions and operations websites and social media pages are, according to the majority of the interviewees, the main platforms of communication. Nowadays, the press release is the traditional communication channel that the information officers use most commonly.

Some of the interviewees as the findings show, find that their press releases are well received by the local media in the host country of the EU deployments. In some missions, specifically Ukraine, television is still the most popular form of communication.

We communicate our activities mainly via our website, social media platforms, media interviews and media events. Our review process shows that TV presence is still possibly the way to get visibility in Ukraine.

An interviewee from the EEAS states that each CSDP mission/operation has a "person appointed to look after communication with the public, the Public Information Officer (PIO) who has a communication budget which they manage locally." According to the official website of EU, this is managed by StratCom Division of the EEAS "provides tailor-made communications guidance and support", and allocates and ensures the communication budgets of CSDP missions and operations.

\subsection{Review of CSDP Media}

A review of the media presence and activities of CSDP missions and operations indicates "a positive and appreciated presence." Most of CSDP's public communication that have been assessed for their research seem to be noncontroversial and descriptive. According to one interviewee from the EEAS,

From the feedback we have received from a number of missions and operations, their communication work is often highly appreciated by partners and local communities as a source of information about the missions/operations mandates, activities and results achieved.

Some missions such as EU NAVFOR conduct continuous review and analysis of their own media presence and feedback. However, measuring public opinion or audience responses based solely on the responses of the public relations team of the missions and operations might not be fully representative of the views of the host country. In terms of target audiences, most of the interviewees stated that their main targets were local audiences such the population in mission and operation locations, local media, politicians, civil societies, and stakeholders. They also target regional and international audiences.

Targeting of audiences within the CSDP draws on the planning and goal-orientated aspects of strategic communication. An interview from the Capacity Building Mission in Somalia (EUCAP) notes, "Target audiences are established by the mission information strategy endorsed by the EEAS." The focus of the missions and operations is the local population while European audiences are targeted by the "EEAS centrally in close coordination with relevant missions" according to an interviewee from the EEAS.

The intentions of the missions and operations communications strategies are mostly "informing or educating" the target audiences about their goals. Some of the missions, as in the case of EU NAVFOR have started to observe the effects of their activities. The intentions when disseminating information to the audience are,

For key audiences to understand our mandate and mission and to support the ongoing activities to deter piracy, protect the vulnerable shipping, support EU missions, and strengthen maritime security around the Horn of Africa.

Similarly, another element of strategic communication is propaganda and public affairs, observable in the responses/activities of EU Mission Ukraine,

The main purpose is to inform them of our work and our existence, but also to explain reform topics, and advocate when possible for speedier reforms (our Head of Mission mainly does this via media interviews.) 
Overall, the fact that the communications of CSDP are strategic can be read in the intentions. Words such as "support and advocate" are widely heard and present in the interview responses. In addition to the provision of information, CSDPs communication are intended to explain but also to draw support, advocate and effect the objectives of the missions and operations.

\subsection{Strategic Communication?}

Before 2011, Stratcom was mainly conducted within the press service of the European Council but with the establishment of the EEAS, the notion of Stratcom also radiated outwards to missions ${ }^{4}$. Most of the interviewees state that strategic communication is applied in their missions and operations. In most cases, the strategies are updated and "framed" annually. The Press and Public Information (PPIO) of each mission and operation develops the information strategy. The objective of the information strategy in Somalia for example is "to ensure that EU CAP Somalia is well understood, accepted and supported in Somalia, including Somalia and internationally." The experiences are similar in other missions including EU NAVFOR, which applies, however, a more dissected strategy targeting specific audiences or sub-audiences,

While coordination across media is essential, the lines of authority for strategic communication and public information will remain separate, to avoid creating media or public perception that public information activities are coordinated by, or are directed by Information Operations (Info Ops) (which targets only prospective targets.) PI does not have a role in planning and executing Info Ops, Psychological Operations (PSYOPs) or deception operations.

Given the limited number of CSDP media outlets and messages, it is difficult to imagine how effective the Info Ops, PSYOPs, PI and strategic communication in general would be. The literature review shows that these types of strategic communication activities require regular, locally understandable, easily accessible and well-resourced interventions.

In terms of success, the two most cited areas of success are social media strategic communications, and the missions/operations' relationship with the local media. Similarly, one of the PPIO heads stated that "hard-hitting and controversial" comments by Mission heads attracted audiences and brought more visibility to the Mission. In the EU NAVFOR case specifically, the role of strategic communication or the PPIO in the achievements of the larger goals of the mission were highlighted.

We are lucky that piracy is universally recognised as crime, and that there is international opprobrium (and there are multinational civilian and military efforts) to deter it. In this sense, we are but one part of the international move to combat piracy. The fact that Somali piracy is largely suppressed cannot be said to be directly due to StratCom efforts, but there is a link.

We find that in terms of practical application of StratCom by CSDP missions, social media followed by radio and printed materials have proven to be successful channels of strategic communication whereas in terms of message "focusing on results and outcomes instead of inputs in connection with the production of attractive audio-visual materials facilitates to reach a wider audience."

\subsection{Challenges}

Common or shared challenges in the process of the application of strategic communications did not emerge from the interviews. The interviewee from the central EEAS office cites their main challenges: resources and lack of experienced personnel in mission and operation locations. In the case of the Ukraine mission, for example, the mismatch of the expectations and demands of the local media and their audience and the Mission's mandates were challenges. In EUCAP Somalia, the very limited PPIO structure and the "security structure in Somalia" were the challenges. EU NAVFOR's challenges are related to language translation, "Having locally translated materials for local audiences in a way that the majority of the local people can access is always a challenge." It would be, then, fair to argue that the challenges are contextual to each mission and operation.

In the words of an EU security and defence strategist, though, the strategic / communication, related challenges of CSDP emanate from EU's/CSDP's own structural problems.

...so when it comes to defence, it is difficult to forge political compromise and on the other, we are talking about very technical issues that there is a structural problem in communicating this effectively and you add on to this the fact that defence cooperation, getting member states to actually produce defence capabilities together extremely complicated. It has to do with harmonizing standards, providing financial incentives, reviewing laws in member states. It even takes time to produce the

\footnotetext{
${ }^{4}$ Personal interview with a staff member of the EEAS in Brussels (November 6, 2017)
} 
capability... Overall, it cannot be said openly because you have all sorts of political resistances but this is what is being done. Often the results take time to show, which creates an inherent problem in communicating this to the public.

The interviewee from the EUAM Ukraine also echoes a similar view "a lot of the improvements depend on strategic/political factors beyond the control of CSDP communications staff."

\subsection{Solutions}

What are the possible solutions to these shortcomings and how could they be improved? The interview findings show that the methods of improving the strategic communication related challenges could start by improving or changing the ways that strategic communication has been implemented such as level of resources, increase of messaging types and channels, and a more structured PPIO network. However, the main solutions have to come from the main structural and administrative framework. In addition, interviewees suggested "key leadership engagement with local authorities", "focus on quality rather than quantity", and timely location and contextspecific solutions to the problems.

Discussing the broader case and potential of strategic communication in the EU's response to the challenge of Fake News and propaganda that mainly comes from Russia and ISIL, the EU's strategist states that the solutions could range from structural to very basic matters,

Having in the EEAS people doing strategic communications is not going to do the trick. It is also a question of the quantity of the people doing it but the instruments, the methods that they use, and also the very basic things, how old they are. Can you really do strategic communication if you are from that generation, if you are aiming at 15,16 and 18 year olds?

The main takeaway from the interview findings is that the main problems within the communication of CSDP are structural and the solutions could possibly start from resolving the structural disharmony.

\section{Discussion and Conclusions}

The purpose of this section is to summarise the findings, compare the findings against the literature review, and conclude the paper with recommendations.

\subsection{CSDP'S StratCom}

The first research question asked if CSDP applied strategic communication, how it was applied, in what forms, with what kinds of targets and intentions. In the literature review, we identified four main forms or characteristics of strategic communication. These forms of strategic communication differentiated it from other forms of mass communication. According to Farwell (2012), the four main forms of strategic communication are Psychological Operations (PSYOPs), propaganda, public information (affairs), and public diplomacy. Based on the analyses of all the active websites of CSDP missions and operations and their social media pages as well as the interview findings, this study finds public information (affairs) and public diplomacy as the dominant forms of strategic communication used by CSDP. Propaganda and PSYOPs are rarely evident from the findings. Public affairs/information, which is the provision of information and explanation of organisational goals and activities, seems to be the main role of CSDP strategic communications of the PPIOs. The interviews and the review of the social media data of CSDP missions and operations found PPIOs carry out a high degree of activity, and greater dissemination of message that could be anticipated under PI . It emerges from the in the interview findings that PPIOs believe their main roles or objectives in strategic communication has been to "inform, explain and educate" whereas "understanding, engaging and influencing" commonly appear in the theoretical definitions of CSDP.

In the majority of the cases of the researched CSDP missions and operations, social media pages publish news items, events and posts portraying the objectives, activities and successes of the EU missions and operations positively. According to the interviewees, while such events and information attract higher visibility, they do not necessarily demonstrate involvement of a grassroots audience. However, perhaps paradoxically, these workshops, training and other high-level events, are quite successful in attracting the attention of the media. Interestingly, social media stands out as the most useful tool of communication for most of the missions and operations. However, the review of the social media pages shows a very limited audience, with little participation and activity from the local communities. This finding shows that the social media accounts of CSDP missions and operations tend to show some features of the echo chamber ${ }^{5}$. It is Europeans interacting with Europeans or stakeholders with stakeholders. The question is how can most of the targeted communities and audiences be reached? How can

\footnotetext{
${ }^{5}$ Barbera (2015) states the online behaviour of most groups and users on the internet shows a characteristic described in media studies as - echo-chamber, where citizens are primarily exposed to like-minded political views.
} 
CSDP missions and operations in Somalia reach the local youth in remote areas on a regular basis? Although the penetration of digital tools has been increasing in most African countries, the level of utilisation is not yet sufficiently recorded; a digital divide is apparent. Similarly, these types of youth or the local population may not even find anything appealing or useful and gratifying on the social media pages of these missions and operations.

Features of PSYOP are occasionally disseminated by the missions and operations according to the interviewees. Examples of this PSYOP include Ukraine, where the PPIO was actively working for "speedier reforms" or EU NAVFOR where the mission applied targeted PSYOPs on "prospective pirates".

The digital media is the main form of communication that is used by CSDP and based on reviews has been creating visibility to the missions and operations. Elizabeth et al (2010) argue that instantaneous, quick response and ability to test salience makes social media ideal for strategic communication. CSDP is therefore ahead in utilising this platform for mainly the purposes of strategic communication. However, the authors argue also, "the deployment of a message through social media can be seen as strategic if it is aimed at a public who uses the social media tool frequently" (Elizabeth et al, 2010: 191). Do CSDP missions and operations target audiences who use social media frequently? The next level of this research shall examine this from the perspective of local audiences. However, based on the findings of this research, most communications by CSDP missions and operations are accessed only by EU stakeholders, rather than the communities in conflict that host their deployment.

When we analyse CSDP's communications based on Cornish et al's (2011) common elements of StratCom, our findings show that CSDP PPI communications do "inform, influence and persuade" their audiences. Secondly, "information fratricide" is not present among missions and operations because the EEAS centrally coordinates each mission/operation's PPIOs. Finally, practical actions are very important for the strategic communications to be effective. Given the accomplishments of the EU globally and the espoused "equalizing and progressive" approach of "working with" rather than "for and to" CSDP's own actions strategically communicate and add to its effectiveness.

Cornish et al (2011) state that effective communications include "a two-way process relaying the reactions and views of the various audiences involved." It is not evident from this research how influential or useful, audience response has been to self -evaluation and appraisal of the strategic communication of CSDP itself. The role and place of audience response in CSDPs strategic communication is not revealed in the interviews or the assessment of CSDPs mass media communication. It could be plausible to interpret that CSDP's StratCom is a one-way process, and focuses on "domestic media relations", "sound-bite" and "photo opportunities" rather than "more subtle strategic message" (Cornish et al, 2011: X). Based on the tenets of the Excellence Theory of strategic communication, CSDP StratCom may be categorised within the PI model of Excellence Theory (communication with no feedback). Therefore, effective strategic communication, which goes "beyond media mission to have developed a targeted campaign of behavioural or social change informed by close knowledge of the audience" is lacking in CSDP.

One EEAS staff member explains that the importance of StratCom has now been recognised and it is going to be widely applied:

Also due to the increasing importance of StratCom (or rather the acknowledgment of such) we are currently in a transition period. There is an increasing demand to communicate the EU's activities outside its borders to the broader public within the EU. This requires clearer guidance as well as from the EEAS Headquarter for example we are currently publishing "impact stories" targeting EU audiences explaining what CSDP personnel are doing and why. In general, the idea is to focus more on the "Why" rather the how and what, when communicating with citizens. Also the linkage between CSDP missions/operations and the security inside the EU will be stressed in future activities ("why is CSDP relevant for your security?").

Strategic communication is understood and has been applied by most of the CSDP missions and operations interviewed and each of them has their communication strategy. With the exception of one Operation, none of the interviewees mentioned Info Ops, PSYOPs, PI or any other specific form of strategic communication or if it has ever been applied. In addition to social media communication, CSDP's relationship with the local media and the interest of the local media in the former or the reproduction of the former's press releases were cited as successes. The next phase of this study would have to assess how CSDP missions and operations are perceived by key audiences in their deployment locations. 


\subsection{Challenges and Solutions}

The second research question asked what the challenges faced by CSDP in terms of communicating CSDP to audiences were and sought possible solutions. The challenges faced by most of the missions and operations differ from one another. The challenges often relate to security in locations, resources, PPIO structure and translation into host languages. PPIOs did not mention any problem in relation to the contents, preparation or implementation of the communication strategies. The small amount of social media activity and visibility, generally limited to a small audience, many of whom are stakeholders, could indicate a lack of creativity, or absence of critical review of previous communication strategies and audience responses. Also, the fact that our findings indicate a one-way CSDP communication process could be described as a shortcoming. It is also remarkable that in only one of the operations, the most advanced types of strategic communication namely, Info Ops and PSYOPs, are mentioned by the interviewee, but nonetheless, in other interviews, strategic communication was considered sufficient or successful in their missions and operations.

However, as stated, the main source of the challenges or shortcomings emanates from the problematic structural issues within the EU/CSDP. Therefore, the main communication related problems of CSDP must also be resolved at the political level. Given what CSDP has been able to achieve so far in practice and the meaningful consequential roles it has played, some solutions are worth recommending. Therefore, in addition to the policy and political level compromises required and the solutions to the structural problems of CSDP, the general absence of two-way communication (in terms of direct audience participation on social media or analysing the reception) must be addressed. Greater focus on PI and public diplomacy is required. Each mission and operations PPIO has its own contextual challenges and shortcomings and they require specific solutions.

The recommendations on CSDP contained in EU Parliament (2016) report are relevant to this study. The EU parliament's report on EU's strategic communications recommend: training and recruiting 'fit for purpose', working beyond merely seeking media attention, focus "story-telling", use of 'real people' rather than wait for actions/facts speak for themselves (ibid.,: 30). As was highlighted in the literature review and the responses of our interviewees, the main challenge to the effective practice of StratCom in CSDP is being under-resourced. Increased resources is, therefore, the major recommendation of this research.

The challenges that face CSDP and the implementation of effective StratCom also affect strategic communication by the missions and operations. For example, the absence of resources, the impact of competing blocs and challenges and threats from Russia impact not just at EU policy level, but also affect strategic communications. CSDP's strengths such as its human rights based approach, EU's reputation as a peace project, experience, geographic proximity and focus on social justice are widely observed in its communication tools, however, they still need to be more visible and strategically communicated. However, opportunities that CSDP has compared to many other security blocs, such as NATO, have not been sufficiently exploited within the social media outputs or did not emerge in the interview findings. What Smith (2014) calls the "local ownership of CSDP" does also seem to be missing in the strategic communication messages since what most of the images and press releases reveal a dominantly one-way communication coming from the EU to the host nation. It is also important and timely that CSDP's PPIO make use of big data to accomplish effective strategic communication.

The research interviews and reviews of the online media outlets of CSDP pages did not explicitly demonstrate what are central to CSDP: gender and human rights. For instance, a case in point is the now defunct EUPOL Afghanistan page, whose Twitter pages regularly sent best Holy Day wishes during each Islamic holiday. In a similar fashion, other CSDP operations and missions attempted to relate and empathise with the communities they were operating in. Their encouraging of human rights and gender issues have not been sufficiently communicated to a wider public. The PPIO interviewees appreciate this and realise that the level of media visibility they receive from local media is important. Equally important is the international media. Despite its records and successes, to date, CSDP does not tend to receive high level media attention compared particularly with other aspects of EU activity or peacebuilding aspects of other similar international blocs, such as the UN. As noted earlier, only one Operation confidently expressed the role of StratCom in its accomplishments of CSDP goals and objectives. Each mission and operation therefore needs to be able to conduct continuous assessment of its StratCom and implementation of a 'fit for purpose' strategy integrated with its wider plans.

This research studied the external communication of CSDP, future research should examine internal strategic communication within CSDP such as between PPIOs and the CSDP leadership or within the management. All stakeholders such as audiences in local populations, regional bodies, Civil Society Organisations (CSOs), local military and civilians as well as regional and international bodies should be considered in terms of effects of the mission or operation, and considered within all analyses of two-sided strategic communication. Inter and intra 
connection of this communication, and a holistic analysis is also important. Hence, the next study should probe if the actions of CSDP and its StratCom actually connect. According to NATO (2016: 44), analysis of StratCom in in Afghanistan, where "policy and operations were well connected and showed results, StratCom amplified that effect." As much as the aim of CSDP is to build peace in their operational and mission locations, it is also the tacit goal of the StratCom and the Union to influence the host nation and add values to affected communities, building the Union's reputation and then political power.

Given recent political eventualities around the world such as the election of Donald Trump as the $45^{\text {th }}$ president of the US in 2016 and Brexit, a renewed emphasis on local politics and policy has been emerging. This creates a vacuum for a trusted, international actor that can fill the void. This is an opportunity for the EU to become the single, trusted, and exemplary global security actor.

\section{References}

Barbera, P. (2015). How social media reduces mass political polarization. Evidence from Germany, Spain, and the U.S. In: Paper prepared for the American Political Science Association conference, New York, pp. 1-6.

Carrasco, C. M., Muguruza, C. C., \& Sánchez, R. A. (2016). Case study: Common Security and Defence Policy (CSDP). Work Package No. 10.

Cornish, P., Lindley-French, J., \& Yorke, C. (2011). Strategic Communications and National Strategy. Chatham House Report, pp. 4.

Dijkstra, H. (2012). Agenda Setting in the Common Security and Defence Policy: An Institutionalist Perspective. Cooperation and Conflict, 47(4), 454-72. https://doi.org/10.1177/0010836712462772

Eder, M. K. (2011). Leading the Narrative: The Case of Strategic Communication. Annapolis (MD): Naval Institute Press.

Ejdus, F. (2017). Here is your mission, now own it! The rhetoric and practice of local ownership in EU interventions. European Security, 1-25. https://doi.org/10.1080/09662839.2017.1333495

Elizabeth, A., Ruthann, L., \& Kaye, D. S. (2010). Social Media and Shared or Divergent-Uses? A Coorientation Analysis of Public Relations Practitioners and Journalists. International Journal of Strategic Communication, 4(3), 189-205. https://doi.org/10.1080/1553118X.2010.489501

European Parliament. (2016). EU Strategic Communications with a View to Counteracting Propaganda: In-depth Analysis, European Union Institute for Security Studies (EUISS) Retrieved February 2, 2017, from https://www.europarl.europa.eu/RegData/etudes/IDAN/2016/578008/EXPO_IDA(2016)578008_EN.pdf

Falkheimer, J. (2015). Strategic Communication. In D-P. Su Mi (Ed.), The SAGE Encyclopedia of Quality and the Service Economy (pp. 770-773). SAGE Publications.

Falkheimer, J., Heide, M., Nothhaft, H., von Platen, S., Simonsson, C., \& Andersson, R. (2017). Is Strategic Communication too important to be left to Communication Professionals? Managers' and coworkers' attitudes towards strategic communication and communication professionals. Public Relations Review, 43(1), 91-101. https://doi.org/10.1016/j.pubrev.2016.10.011

Farwell, J. P. (2012). Persuasion and power: the art of strategic communication. Washington, DC: Georgetown University Press.

Hallahan, K., Holtzhausen, D., van Ruler, B., Verčič, D., \& Sriramesh, K. (2007). On defining strategic communication. International Journal of Strategic Communication, 1(1), 3-35. https://doi.org/10.1080/15531180701285244

Holtzhausen, D., \& Zerfass, A. (2014). The Routledge Handbook of Strategic Communication. New York: Routledge. https://doi.org/10.4324/9780203094440

James, W. (2015). Common Security and Defence Policy (CSDP), CIVITAS Institute for the Study of Civil Society. Retrieved February 22, 2018, from http://www.civitas.org.uk/content/files/EX.4.CSDP_.pdf

Kumar, K. (1989). Conducting Key Informant Interviews in Developing Countries. A.I.D. Program Design and Evaluation Methodology Report. Retrieved February 22, 2018, from https:/www.scirp.org/(S(lz5mqp453edsnp55rrgjct55))/reference/ReferencesPapers.aspx?ReferenceID=151 4350

Lange-Ionatamishvili, E., \& Svetoka, S. (2015). Strategic Communications and Social Media in the Russia Ukraine Conflict. In K. Geers, (Ed.), Cyber War in Perspective: Russian Aggression Against Ukraine (pp. 107). Tallinn: 
NATO CCDCOE Publications.

Melissen, J. (2005). The New Public Diplomacy: Soft Power in International Relations. Hampshire: Palgrave MacMillan. https://doi.org/10.1057/9780230554931

North Atlantic Treaty Organisation (NATO). (2016). "WE HAVE MET THE ENEMY AND HE IS US" An Analysis of NATO Strategic Communications: the International Security Assistance Force (ISAF) in Afghanistan, 2003-2014. NATO Strategic Communications Centre of Excellence: Latvia.

Nulle, A. (2014). The Common Security and Defence Policy of the EU. A Neo-Institutionalist Analysis of a Policy Field in Paralysis [unpublished]. Thesis, Linköping University Linköping.

Paul, C. (2011). Strategic communication: Origins, concepts, and current debates. Santa Barbara, CA: ABC-CLIO.

Phillips, C. D. (2012). Toward a Theory of Strategic Communication: A Relationship Management Approach [unpublished].., In partial fulfilment of the requirements of the Master of Strategic Studies Degree, United States Army War College.

Smith, M. E. (2014). Intelligence Analysis, Policy Planning, and Consensual Knowledge in EU Security Operations. 8th Pan-European Conference on International Relations. Retrieved July 17, 2017, from http://www.eisa-net.org/be-bruga/eisa/files/events/warsaw2013/Smith_CSDPIntelPlanning.pdf

Vernon, L. (2013). A Rhetorical Analysis of Strategic Communication in the Amalga Barrens Wetlands Controversy. All Graduate Theses and Dissertations. Paper 1704.

Wilbur, D. (2017). Propaganda's Place in Strategic Communication: The Case of ISIL's Dabiq Magazine. $\begin{array}{llll}\text { International Journal of Strategic Communication, } & 11, \quad 223 .\end{array}$ https://doi.org/10.1080/1553118X.2017.1317636 


\section{Appendix 1}

Review of CSDP's social media outlets, assessed at the end July 2017

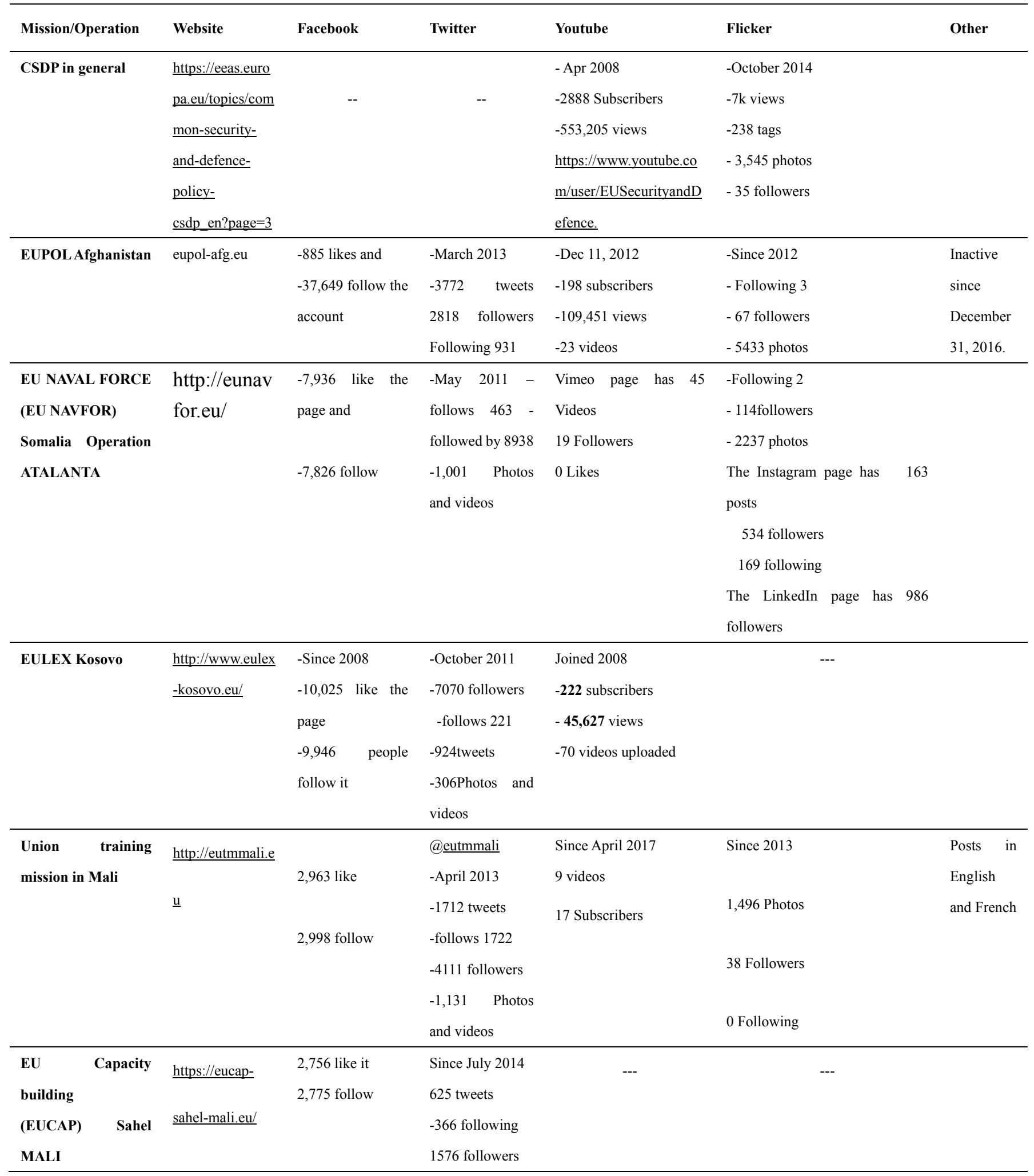




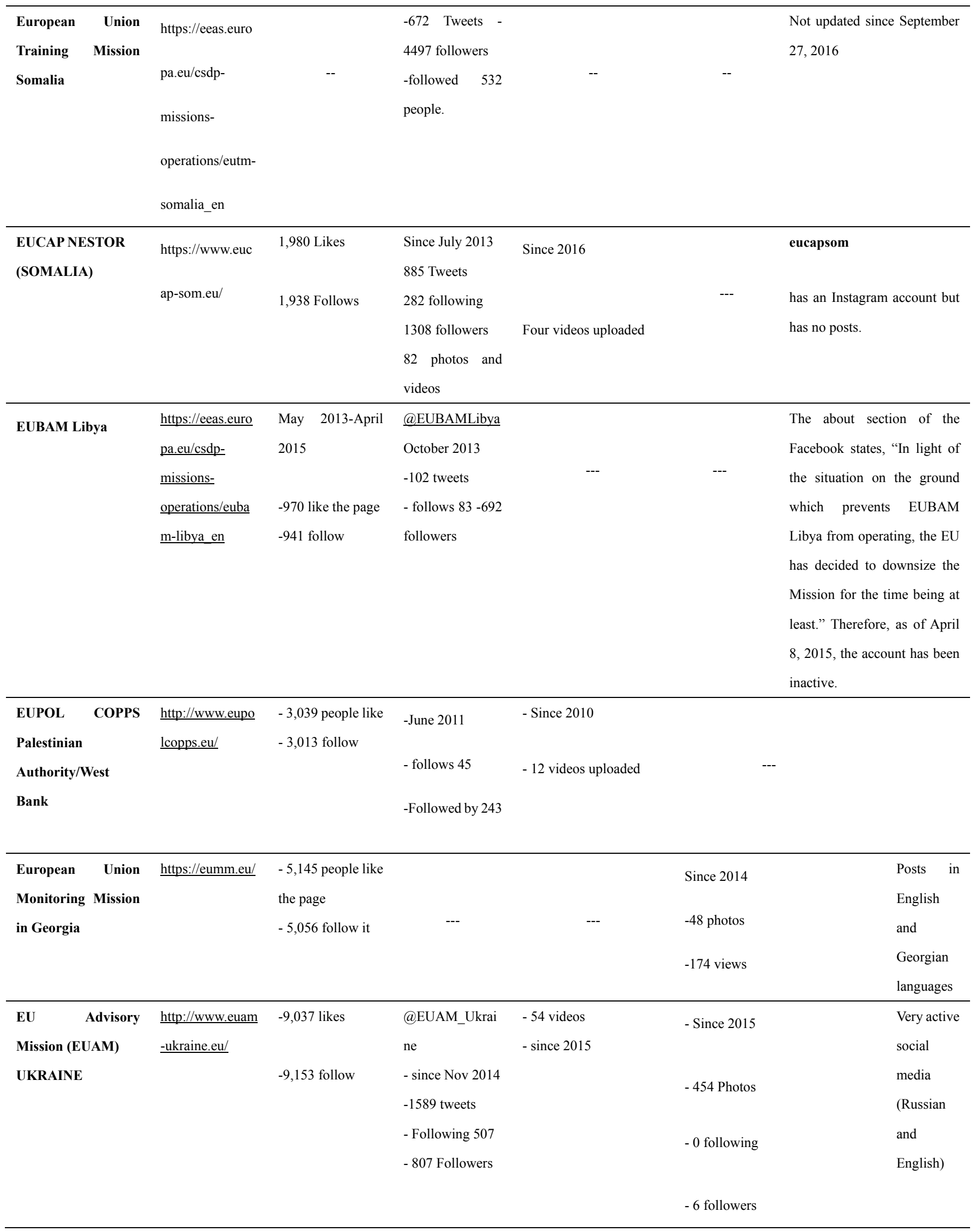




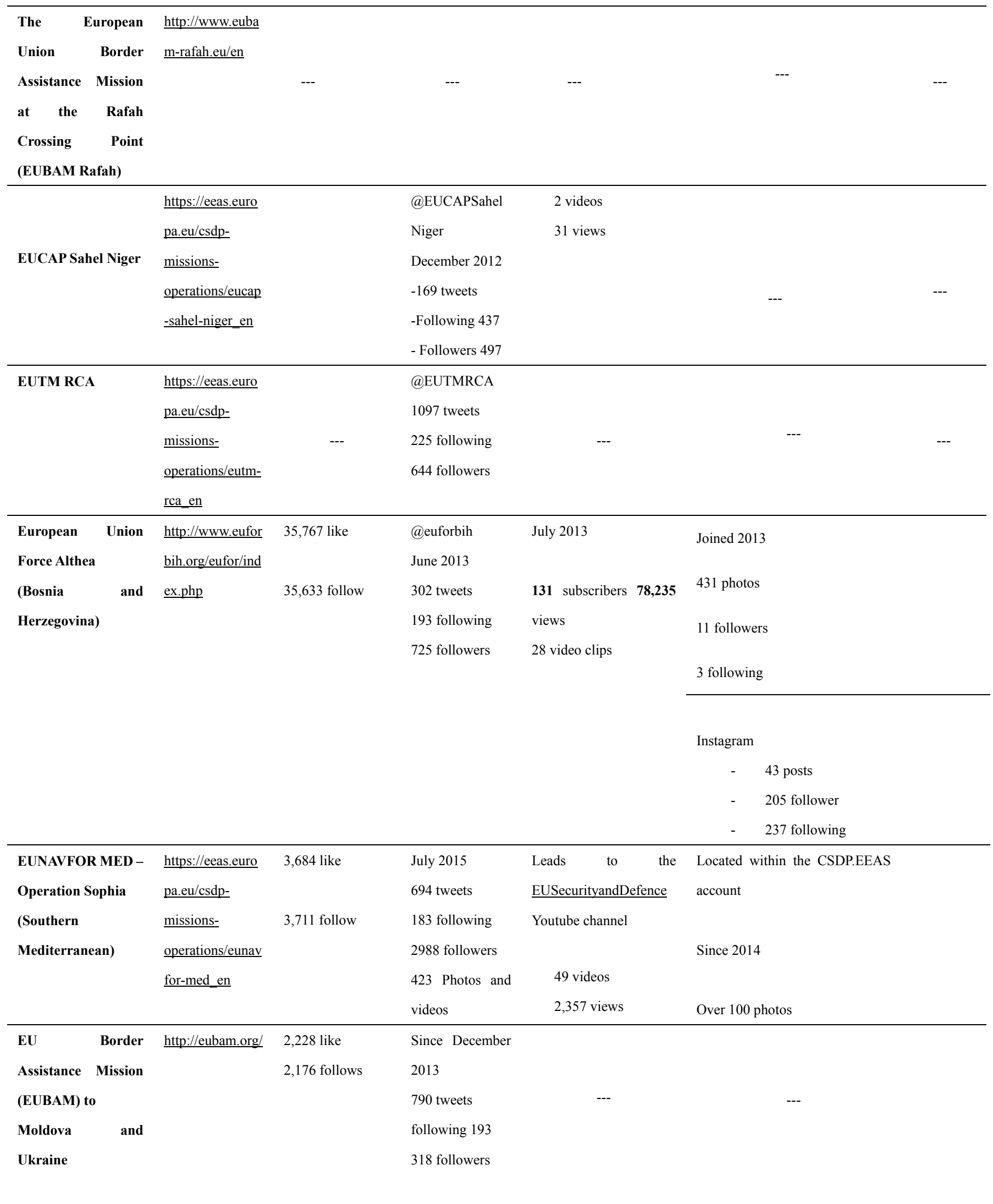

Table 1 (assembled by the author) 


\section{Copyrights}

Copyright for this article is retained by the author(s), with first publication rights granted to the journal.

This is an open-access article distributed under the terms and conditions of the Creative Commons Attribution license (http://creativecommons.org/licenses/by/4.0/). 